\title{
Canadian Journal of Zoology
}

Canadian

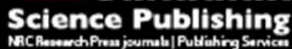
Revue canadienne de zoologie

The role of sensory modalities in producing nonconsumptive effects for a crayfish-bass predator prey system

\begin{tabular}{|r|l|}
\hline Journal: & Canadian Journal of Zoology \\
\hline Manuscript ID & cjz-2017-0109.R1 \\
\hline Manuscript Type: & Article \\
\hline Complete List of Authors: & $\begin{array}{l}\text { Clark, Jessica; Bowling Green State University Department of Biological } \\
\text { Sciences; University of Michigan Biological Station } \\
\text { Moore, Paul ; Bowling Green State University, Biological Sciences; } \\
\text { University of Michigan Biological Station }\end{array}$ \\
\hline Keyword: & $\begin{array}{l}\text { sensory modalities, multimodality, sensory hierarchy, predator-prey } \\
\text { interactions, nonconsumptive effects, Largemouth bass (Micropterus } \\
\text { salmoides), rusty crayfish (Orconectes rusticus) }\end{array}$ \\
\hline \multicolumn{2}{|c}{} \\
\hline
\end{tabular}

SCHOLARONE ${ }^{\prime \prime}$

Manuscripts 

predator prey system

Jessica L. Clark ${ }^{1,2}$ and Paul A. Moore ${ }^{1,2}$

${ }^{1}$ Department of Biological Sciences, Laboratory for Sensory Ecology

J.P. Scott Center for Neuroscience, Mind, and Behavior

Bowling Green State University, Bowling Green OH, 43403, USA

${ }^{2}$ University of Michigan Biological Station

9133 Biological Road, Pellston, MI, 49769, USA

*Corresponding author pmoore@bgsu.edu 


\title{
The role of sensory modalities in producing non-consumptive effects for crayfish-bass predator
} prey system

\author{
J. L. Clark and P. A. Moore
}

\begin{abstract}
\end{abstract}
The impact of non-consumptive effects in structuring predator-prey interactions and trophic cascades is a prominent area of ecological research. For non-consumptive effects to occur, prey need to be able to detect the presence of predators through sensory mechanisms. The investigation of the role of different sensory modalities in predator detection has lagged behind the development of NCE based theories. This study aimed to determine whether a hierarchy in the reliance upon sensory modalities exists in Orconectes rusticus (Girard, 1852) for predator detection and if this hierarchy is altered across different sensory environments (flowing and non-flowing environments). Crayfish were exposed to Micropterus salmoides (Lacépède, 1802) odor in either a flowing or non-flowing arena where behavior was recorded under different sensory lesions. Linear mixed models were conducted to determine the impact of lesions, flowing environments, and the interactive effects of lesions and flowing environments on the crayfish ability to respond to predatory stimuli. Results from this study support the significance of sensory multimodality in crayfish for accurately detecting and assessing predatory threats. Results from this study also suggest a hierarchy in the reliance upon sensory modalities in crayfish which is dependent upon the environment and the location of crayfish within an environment.

Key words: sensory modalities, multimodality, sensory hierarchy, predator-prey interactions, nonconsumptive effects, rusty crayfish (Orconectes rusticus), Largemouth bass (Micropterus salmoides) 
Introduction

Predators impact ecosystems through consumptive and non-consumptive effects. Consumptive effects (CEs), defined as the direct physical interactions between predators and prey, impact prey populations by reducing the density of populations through the act of consumption (Davenport and Chalcraft 2013; Turner and Peacor 2012; Weissburg et al. 2014). Examples of consumptive effects include Helicoverpa armigera (Hübner, 1808) larvae feeding on Australian cotton crops (Rendon et al. 2015 ) to a lion attacking and consuming a gazelle. Non-consumptive effects (NCEs) are defined as the indirect interactions between predators and prey (Davenport and Chalcraft 2013; Elvidge and Brown 2015; Weissburg et al. 2014). These indirect interactions refer to the factors of intimidation prey

41 demonstrate while in areas of previous and potential predatory threats. For example, several species of

42 Daphnia increase their body size, reducing their chances of predation by smaller fish, with the addition of 43 spines, neckteeth, and/or helmets in response to kairomones released by predators (Dzialowski et al. 44 2003; Preisser et al. 2005). Multiple studies have shown that NCEs can have greater impacts on the 45 dynamics of prey populations as compared to CEs (Preisser at al. 2007; Rendon et al. 2015; Sih et al. 46 2010; Turner and Peacor 2012; Weissburg et al. 2014).

NCEs occur when the threat of predation alters the behavior and/or life cycles of prey species

48 (Lima and Dill 1990). These short- and long-term behavioral and morphological changes caused by NCEs

49 include reduced foraging, avoidance of certain areas within a habitat, and altered growth rates (Davenport and Chalcraft 2013; Larsen 2012; Preisser at al. 2007; Weissburg et al. 2014). After grey wolves were reintroduced to Yellowstone National Park, the population of elk reduced foraging on aspens, which

52 resulted in an increase in the growth of aspen trees and other native plants (Ripple and Beschta 2006). In

53 the presence of Mojave Desert sidewinders (Crotalus cerastes [Hallowell, 1854]), two species of 54 kangaroo rats (Dipodomys deserti [Stephens, 1887] and D. merriami [Mearns, 1890]) avoided certain 55 areas of the experimental habitat (Bouskila 1995). Previous studies, including those mentioned, have 

57 species.

shown the impact NCEs have on food webs within ecosystems and on the behavioral decisions of prey

Most often the response of prey upon the detection of predatory signals is avoidance, which has been called a "fear" response (Laundré et al. 2010). From such concepts, arose the "landscape of fear" theory (Laundré et al. 2010). Several studies have shown that prey alter their use of the landscape according to a perceived threat of predation (Elvidge and Brown 2015; Fine et al. 2011; Laundré et al. 2010; Weissburg et al. 2014). Laundré et al. (2010) demonstrated how mule deer (Odocoileus hemionus) alter their use of a landscape according to predation risk of pumas (Puma concolor L.). Most often the deer were documented to avoid the forest edges, where pumas are successful hunters, and preferred open areas, where pumas are not as efficient at hunting (Laundré et al. 2010). When exposed to visual and chemical cues of predatory largemouth bass (Micropterus salmoides), even with no physical interaction, juvenile channel catfish (Ictalurus punctatus [Rafinesque, 1818]) reduced foraging habits (Fine et al. 2011). This foraging reduction resulted in slower growth rates compared to control groups with no exposure to predatory threats (Fine et al. 2011). This landscape of fear can be dependent upon the sensory landscape within individual inhabits.

Jurcak and Moore (2014) defined sensory landscape as the temporal and spatial distribution of stimuli throughout an individual's environment. The sensory landscape for organisms is created by the presence of others, such as prey, conspecifics, and predators, and the transmission of sensory signals through the environment (Jurcak and Moore 2014). Each unique predator creates a set of sensory stimuli, whether those stimuli are visual, chemical, auditory, or mechanical, detectable by prey. For example, avian predators cast shadows from above and/or create disturbances in the treetops with the beating of their wings, alerting prey of their presence (Lohrey et al. 2009). Also, ambush predators, such as snakes, secrete chemical cues (kairomones) into the environment which species of prey, including lizards, can detect their presence (Cabido et al. 2004). However, the sensory landscape can be dependent on the characteristics of the landscape itself. 
The mixing, dispersal, and quality of stimuli throughout an area is reliant upon the habitat in

82 which it occurs. Highly turbid environments will limit the transmission of light, and therefore, visual cues

83 (whereas turbidity does not likely affect chemical cues; Lunt and Smee 2015; Weiss et al. 2012). The

84 wind speed of terrestrial systems and the hydrodynamic forces of aquatic systems, including flow velocity

85 and turbulence (Hazlett et al. 2006), can affect the structure of odor plumes. When the fine scale structure

86 of odors are altered, the spatial and temporal information within the plume alters an organism's behavior

87 (Turner and Peacor 2012; Weissburg 2012). Over contrasting substrates, odor plumes distribute at

88 different rates and concentrations, affecting the distribution of information (Wolf et al. 2009).

89 Obstructions in the landscape, such as trees and rocks, can disrupt the flow of signals through the

90 environment, including blocking visual cues and/or accumulating chemical cues in certain areas.

91 Conversely, sound travels at a higher speed in aquatic environments as opposed to terrestrial ones.

92 Mechanical/tactile cues are limited to short distances (Weissburg et al. 2014). The sensory landscape, as

93 described above, contains the stimuli from which prey extract information about the threat of predation.

Aquatic organisms rely upon multiple sensory mechanisms to detect potential predators. Most

95 often chemoreception, mechanoreception, and vision are utilized to assess predatory threats (Smith and

96 Dunham 1990; Weiss et al. 2012). Chemical cues provide prey species with the locality of the threat and

97 the degree of threat (higher concentrations of chemical cues can indicate a predator, or multiple predators,

98 are nearby; Weiss et al. 2012). The reception of mechanical cues indicates the movement of the predators

99 in close proximity (Weiss et al. 2012). Visual cues provide information of the characteristics, such as

100 body size/shape, of predators within a limited distance (Smith and Belk 2001). The integration of such

101 sensory mechanisms allows organisms to assess predatory threats with accuracy and thus respond in a

102 proper way (Partan and Marler 2005). Studying the function of sensory modalities can further distinguish

103 the significance of modality integration, an individual's reliance upon such modalities, the information

104 gathered from each, and how individuals use the information gathered to make decisions to limit the 
likelihood of predation. This study focused on the importance of sensory integration and whether a hierarchy of reliance upon sensory mechanisms exists in crayfish.

By limiting the functional sensory modalities of crayfish (Orconectes rusticus) to a single modality, we hoped to determine the degree of multimodality that occurs during predatory threats, which in turn allows us to determine how each sense influences the NCEs caused by predatory largemouth bass (Micropterus salmoides). Orconectes rusticus inhabit both flowing (rivers and streams) and non-flowing (lakes and ponds) environments (Bergman et al. 2006) and have been shown to rely on vision, chemoreception, and mechanoreception to detect nearby prey and potential predators (Callaghan et al. 2012). This multimodality and ubiquitous presence in aquatic habitats made Orconectes rusticus appropriate experimental organisms for this question. Micropterus salmoides are known predators of Orconectes rusticus and their presence has been shown to alter the behaviors of crayfish (Keller and Moore 2000). Through sensory lesions/blocks the multimodality of Orconectes rusticus was limited to one functional sensory mechanism, either chemoreception, mechanoreception, or vision alone.

Orconectes rusticus were then exposed to two environmental conditions, flowing and non-flowing arenas, to further distinguish the role of sensory modalities and the impact of environmental conditions.

\section{Methods}

Animals (Collection and Holding):

Rusty crayfish, Orconectes rusticus, were collected from Maple Bay in Burt Lake, MI (lat. $45^{\circ} 28^{\prime} \mathrm{N}$, long. $84^{\circ} 40^{\prime} \mathrm{W}$ ) throughout the summer of 2016 by use of hand nets. Both adult males and females (post orbital carapace length: mean $\pm \mathrm{SEM}=3.06 \pm 0.033 \mathrm{~cm}$ ) were used. All individuals were in form II (non-reproductive), free from injuries and had all appendages (chelae and walking legs), including sensory appendages (antennules and antennae), intact. Crayfish were housed at the University of Michigan Biological Station Stream Research Facility in streams made of cinder blocks lined with plastic sheeting (304.8 $\mathrm{cm}$ x $81.3 \mathrm{~cm}$ x $40.6 \mathrm{~cm} ; L: W: H)$. Unfiltered water from the nearby Maple River was pumped into the holding streams, which provided crayfish with river water and detritus. Within the 
streams, crayfish were housed individually in Tupperware containers $(18.1 \mathrm{~cm}$ x $16.2 \mathrm{~cm}$ x $7.3 \mathrm{~cm}$;

132 minimum of one week before use in trials. This isolation ensured a limited diet of natural detritus and no

133 interactions with other individuals that could have resulted in dominant and subordinate statuses of

134 individuals (Karavanich and Atema 1998).

Thirty adult male and female (12.7 cm - $25.4 \mathrm{~cm}$ standard length) largemouth bass, Micropterus salmoides, were provided by Harrietta Hills Trout Farm in Harrietta, MI. The bass were equally divided

137 and housed in two flow-through metal horse troughs $(237.5 \mathrm{~cm} \times 86.4 \mathrm{~cm} \times 60.1 \mathrm{~cm} ; L: W: H)$. Unfiltered water from the nearby Maple River filled the holding troughs. A sand substrate, approximately $2 \mathrm{~cm}$ deep, covered the bottoms of the troughs to reduce the risk of physical injury to the fish. Several PVC Pipes were provided as shelters for the bass. Window screening covered the tops of the troughs to prevent the

141 loss of fish to predatory animals. The fish were fed a diet of Purina Aquamax Sport Fish/ Grower 600 142 pellets every day.

Monitoring health and safety of fish: and PRO00004591 (Michigan). The bass were monitored for signs of distress and disease throughout their time in the holding troughs and during trials. If/when signs of stress, such as strange swimming

147 patterns or gasping at the surface of the water, were displayed by an individual, the bass was removed 148 immediately from their housing trough or experimental arena. Once removed, the fish were transported in 149 a cooler equipped with an aerator and placed into a quarantine tank located inside the Stream Research 150 building. While quarantined, the stress levels of the fish were monitored. Fish that displayed any signs of 151 disease were also removed from the holding streams and placed into quarantine tanks. The quarantine 152 tanks allowed for the administration of antibiotics and close monitoring, along with minimizing the 153 spread of disease. Fish that displayed any signs of distress or disease were not used in the trials. 
Experimental design:

A 2 x 4 fully factorial experimental design was conducted to examine the dependence of sensory mechanisms utilized by crayfish to detect predators in different flow environments, with flow as one treatment and sensory mechanisms as the second treatment. Within the flow treatment, two conditions existed (flowing and non-flowing). Within the sensory mechanism treatment, a total of four treatment conditions, three lesions/blocks and one control, were created. For each treatment within the sensory mechanisms condition, one sensory channel remained active, while two sensory channels were either blocked or lesioned. For example, in the chemical active treatment, mechanoreceptors and vision were blocked while chemoreception was sham lesioned, leaving this sense active. In a similar way, the mechanical active treatment had a sham block performed on the mechanoreceptors with vision being blocked and chemoreceptors being lesioned. In the visual active treatment, vision had a sham lesion, while mechanoreceptors were blocked and chemoreceptors were lesioned. In the control condition, shams were performed on all three sensory mechanisms. Each of the four conditions were replicated 10 times in both environments, for a total sample of 80 crayfish. Details for the sham and lesion techniques follow this section. While the mechanical and visual mechanisms were technically blocked rather than lesioned, we will use the term lesion for all three treatments for ease of communication.

\section{Restraint and handling of crayfish through the lesioning process:}

Once selected for a treatment, crayfish were physically restrained, ventral side down while facing downward, and placed on a bath of well water $\left(5^{\circ} \mathrm{C}\right)$ for at least 2 minutes. The restraints limited the movements of the individuals throughout the process, while the cold water helped to further slow their movements. After the exposure to well water, the lesioning process began. During this process the restraint boards stood at a slight angle (approximately $70^{\circ}$ ), ensuring that water did not spill from the antennule reservoirs (micro-pipette tips). River water was applied to the gills and along the body of the crayfish every 10 to 15 minutes. The health of the crayfish was monitored throughout the process. The total duration of the lesioning process, and the amount of time crayfish were restrained, was 2 hours and 
17910 minutes. Once the crayfish were exposed to the appropriate combination of lesions and/or sham lesions 180 the individuals were placed in their holding containers to await trial the next morning.

181 Chemical lesion/sham

182 Chemical lesion: All four antennules (lateral and medial filaments) of the crayfish were placed in a 183 reservoir (micro-pipette tip) filled with $50 \mathrm{ppt}$ saltwater for 2 hours (Kraus-Epley et al. 2015). To ensure 184 the antennules were exposed to the saltwater throughout the 2 hours, additional saltwater was added to the 185 reservoir as needed. The saltwater within the reservoirs was also replaced after each watering of the 186 crayfish, every 10 to 15 minutes. After 2 hours of exposure, the saltwater was replaced with deionized 187 water for 10 minutes. This change in osmotic pressure lysed the dendrites of chemoreceptors while the mechanoreceptors remained intact (Belgane et al. 1997; Kraus-Epley et al. 2015). This technique has been used for lesioning chemoreceptors of crayfish in several past studies and has proven to provide an effective chemosensory lesion (Belgane et al. 1997; Kraus-Epley et al. 2015).

191 Chemical sham: Both pairs of antennules were placed in a reservoir filled with river water, from the 192 crayfish holding stream, for 2 hours and 10 minutes (the same duration as treated animals). To ensure the antennules were exposed to the river water for the entire time the reservoir was filled with water every 10 to 15 minutes, or as needed.

\section{Visual lesion/shams}

196 Visual lesion: To block the reception of any visual cue/signal, thin black flexible goggles were placed 197 over the eyes of the individuals. While restrained and antennules in reservoirs, a small wooden peg (4.7 \pm $1980.2 \mathrm{~mm}$ long and $2 \mathrm{~mm}$ round) was secured to each side of the carapace, just behind the eyes, with 199 Loctite ${ }^{\circledR}$ brand epoxy. The epoxy was allowed to dry completely. Correct size goggles, large or small, 200 were then selected based on the size of each individual. Black goggles were made by mixing the standard

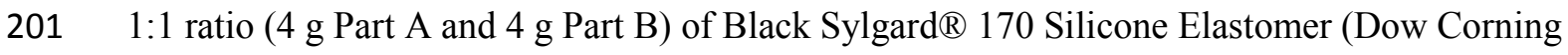

202 Corporation, Midland, MI). A thin layer $(0.8 \pm 0.08 \mathrm{~mm})$ of the mixture was then poured into a glass 
Pyrex ${ }^{\circledR}$ petri dish cover $(9.3 \mathrm{~cm}$ in diameter and $1.1 \mathrm{~cm}$ deep). Seven to ten metal ball bearings $(5 \mathrm{~mm}$ in diameter and $7 \mathrm{~mm}$ in diameter) were then strategically placed in the dish. The dish was placed in an oven at $125^{\circ} \mathrm{C}$ for 30 minutes, or until the mold had cured. Once the mixture had hardened, the dish was removed from the oven and allowed to cool. A small metal spatula was then used to carefully remove the

207 Sylgard ${ }^{\circledR}$ mold from the dish. The ball bearings were then removed from the mold, leaving a circular

208 indentation. Teardrop shaped metal cutters were used to shape the goggles, ensuring that the

209 larger/rounder end of the shape was around the circular indentation in the molds. The small goggles were 210 created from the molds with $5 \mathrm{~mm}$ indentations, which were shaped with a $1.85 \mathrm{~cm} \times 1.3 \mathrm{~cm}(L: W)$

211 teardrop shaped metal cutter (Figure 1A). The $2.5 \mathrm{~cm} \mathrm{x} 1.85 \mathrm{~cm}(L: W)$ metal cutter was used to make the 212 larger goggles from the molds with the $7 \mathrm{~mm}$ indentations (Figure 1B). Once the correct size of goggles 213 was selected, the goggles were cutout and trimmed to best fit for each animal. Goggles were held in the correct positon on the animal, eye in eye slot and goggle not in the way of the antennae, and the location of the hole for the peg was marked (using a Sharpie ${ }^{\circledR}$ marker). A $3 \mathrm{~mm}$ hole was then punched, using a cork borer, in the goggle. One at a time, the goggles were positioned correctly on the pegs, being sure the

217 eyes were blocked, and secured in place with Loctite ${ }^{\circledR}$ brand Super Glue. The super glue was allowed to 218 dry.

219 Visual sham: Using the same application methods as black goggles above, clear goggles were applied to 220 the control individuals. The clear goggles were made following the same protocol as the black goggles; 221 however, the standard 10:1 ratio (10 grams of the base to 1 gram of the curing agent) of Sylgard® 184 222 Silicone Elastomer was used. When the clear goggles were applied correctly the vision of the crayfish 223 was not hindered in any way and therefore remained active. conducted. In the lab, 10 control animals (crayfish without goggles) and 10 experimental animals

226 (crayfish with clear goggles) were exposed to a scare stimulus (a row of 3 ping pong balls coming 227 towards them; Rapin and Moore 2016). The distance between the scare stimulus and the initiation of a 

conditions exhibited similar response distances; therefore, we concluded that the goggles had no impact on their vision.

Goggled animals were also exposed to slightly increasing flow velocities (from $5 \mathrm{~cm} / \mathrm{s}$ to 15 $\mathrm{cm} / \mathrm{s}$ ) in the lab. The findings from this exposure ensured that the goggles would not flap up during the flowing trials and therefore the animals remained blinded throughout.

\section{Mechanical lesion/sham}

235 Mechanical lesion: While restrained, Gorilla® Super Glue was applied with a brush applicator along the 236 entirety of the antennae, making sure to cover each of the aesthetasc hairs, which, when applied correctly, 237 blocked the mechanoreceptors along the antennae thus inhibiting the collection of mechanical cues 238 (Kraus-Epley and Moore 2002). Once the glue had dried the mechanoreceptors were then considered 239 lesioned. This lesioning technique has been used for blocking mechanoreceptors of crayfish in past 240 studies and has been shown to be an effective mechanical, and not chemoreceptor, lesion (Kraus-Epley 241 and Moore 2002).

242 Mechanical sham: Gorilla ${ }^{\circledR}$ Super Glue, similar to the amount applied to experimental crayfish, was 243 applied to the base of the carapace of the individuals. This was to ensure that the odor of the glue had no 244 effect on the behavior of the crayfish. The antennae were then washed with a $1 \mathrm{~mL}$ pipette filled with 245 river water. This was to replicate the stimulation of antennae in which experimental animals were exposed 246 to in the gluing process. The super glue was allowed to dry. The mechanoreceptors were not altered in 247 any way and therefore remained active.

Experimental Arena: 
$81 \mathrm{~cm} \times 21 \mathrm{~cm}(L: H)$ piece of plywood with $8 \mathrm{~mm}$ holes at the opposite end of the stream. The water level remained at a depth of $20 \mathrm{~cm}$. Nylon stockings placed over the supply pipe helped reduce the quantity of macroinvertebrates and fine organic matter in the water. The bottom of the arenas were covered with approximately $2 \mathrm{~cm}$ of sand. Arenas were divided into two areas, upstream for the bass, $40 \mathrm{~cm} \mathrm{x} 81 \mathrm{~cm} \mathrm{x}$ $41 \mathrm{~cm}(L: W: H)$, and downstream for the crayfish, $81 \mathrm{~cm} \times 81 \mathrm{~cm} \mathrm{x} 41 \mathrm{~cm}(L: W: H)$. The two areas were separated by egg crating, which allowed the individuals to visually, chemically, and mechanically sense each other but avoid any physical contact. The downstream/crayfish area of the experimental arenas 259 contained a shelter along the right wall, $30 \mathrm{~cm}$ from the egg crating divider, and a food source along the 260 left wall, opposite the shelter. The shelters were made of PVC pipes cut in half $(8.3 \mathrm{~cm} \times 7.6 \mathrm{~cm} ; L: D)$ attached to a Plexiglas ${ }^{\circledR}$ base. The available food source consisted of a small plastic cap $(2.5 \mathrm{~cm}$ in diameter and $1 \mathrm{~cm}$ deep) filled with fish gelatin. The fish gelatin was made by mixing 28 grams of Knox's ${ }^{\circledR}$ unflavored gelatin, 46 grams of homogenized canned sardines, and $600 \mathrm{ml}$ of boiling water

264 (Wolf et al. 2004). This gelatin mixture was then poured into individual small plastic caps and allowed to set in a refrigerator for 12 hours. Caps of food were only used for one trial.

During the 15 minute acclimation periods for both the flowing and non-flowing arenas, a non-

267 porous divider, $81 \mathrm{~cm} \times 25.4 \mathrm{~cm}(L: H)$ plywood, was placed beside the egg crating to prevent mixing of 268 stimuli between the bass and crayfish sections (Figure 2). To ensure that both animals received constant 269 flow during acclimation for the flowing trials, a secondary outflow (for the bass) and a secondary inflow 270 (for the crayfish) were constructed. This allowed water to enter in the upstream (bass) area and exit right 271 before the barrier. On the opposite side of the barrier (downstream/crayfish area), water entered from 272 secondary hoses from the head tank and then exited in the outflow of the arena. Once the acclimation 273 period ended, these secondary inflow and outflow were deactivated and the non-porous divider removed, 274 leaving only the egg crating divider between the animals and the trails began. The non-flowing arenas 275 (Figure 2) were identical in size and shape and were constructed of the same materials as the flowing arenas, but there were no inputs or outputs of water, the hoses from the head tank were removed and the 
277 holes in the outflow were plugged. After the 15 minute acclimation periods for the non-flowing arenas, 278 the non-porous dividers were removed and the trials began. Using four low light security cameras (Model 279 \#PRO-615) mounted on a wooden structure above the arenas, the behaviors of the crayfish were recorded 280 from above. The cameras were connected to a SWANN DVR4-3250 model DVR housed within the 281 Stream Research building where the trials were recorded for further analysis. Black tarps $(9.1 \mathrm{~m} \times 9.1 \mathrm{~m}$; $282 L: W)$ covered the wooden structure above the arenas to ensure consistent lighting throughout each of the 283 trials. Four 25W A19 red transparent lightbulbs were arranged on the structure to provide lighting. Starvation, Acclimation, and Protocol:

Each of the crayfish were housed in Tupperware for a minimum of 7 days before use in trials. During the 7 days, the Tupperware limited the amount of natural detritus available to the animals. This limited diet was implemented to increase motivation for foraging during trials. Due to their role in the experimental trials, limited to simply providing the presence of a predator, the bass were not starved.

Before each of the trials began, a fresh food cap was weighed and placed in the correct location, along with the shelter, in the downstream/crayfish area of the arena. The non-porous divider, as well as 291 the hoses and secondary outflows for the flowing trials, were placed in the correct position before the 292 trails began. For each of the trials, one crayfish and one bass were selected at random. Crayfish were used 293 for only one trial each while bass, due to a limited quantity, were used for multiple trials. The handling 294 time for each animal was as limited as possible. Using a fine net, bass were individually collected from 295 the holding trough and placed in a cooler equipped with an aerator and filled with river water. From the 296 cooler the bass were transported to the upstream area of the experimental arena. The selected crayfish, 297 once lesioned the day before, was marked with whiteout along the back of the carapace and the top of the 298 chelae before the trials began. Once marked, the crayfish were safely transferred, in Tupperware, and 299 released into the downstream area of the arena. With the non-porous divider in place, both individuals 300 were allowed to acclimate simultaneously for 15 minutes. This acclimation time allowed both the bass 
301 and the crayfish to adjust to their new surroundings before being exposed to one another. Once the 302 acclimation period was complete, the non-porous divider was removed and the trials began.

The trials took place between the hours of 08:00 and 12:00. Each of the trials ran for 30 minutes.

304 Once the trials were complete, the food cap was collected and weighed and the fish were placed in the 305 cooler and carried to their holding troughs. Due to the lesioning of sensory mechanisms and to comply 306 with our DNR permit, the crayfish were frozen. The arenas were allowed to flush for a minimum of one 307 hour between trails.

Data Analysis:

\section{Path Digitization}

To quantify any effect that sensory lesions may have had on predator mediated behaviors, one

311 point on the carapace of the crayfish was used to generate an $x, y$ position during the entire 30 minute

312 trials. A single point on the animals was used because crayfish can move backwards and sideways while

313 keeping their sensory apparatus pointed toward a stimulus. So, we wanted to capture movement of the 314 animals as opposed to body orientation of the animals. The movements made by each individual were 315 analyzed using Ethovision Noldus XT (Leesburg, Virginia, USA), a motion tracking software. Using the $316 x, y$ data points, the position of the crayfish was recorded every second and the $x, y$ points were analyzed 317 to determine movement patterns within the arena. Previous work has shown that this level of spatial 318 resolution provides an excellent assessment of movement (Moore and Grills 1999; Moore et al. 2015; 319 Wolf et al. 2004). In addition, crayfish tracks were compiled using these data and we extracted the 320 following behavioral measures.

\section{Behavioral Measures}

From the $x, y$ data points we could determine the total time crayfish spent in each of the zones of

323 the arena. The downstream/crayfish area of the experimental arenas were equally divided into three zones.

324 The threat zone was defined as the area closest to the upstream/fish area of the arena. The middle one- 
third, which consisted of the shelter and food cap, was defined as the resource zone. The section furthest from the fish and containing no resources was defined as the empty zone.

The animal was considered walking when its moving speed was greater than $0.5 \mathrm{~cm} / \mathrm{s}$ and 328 considered stationary when the walking speed was lower than $0.5 \mathrm{~cm} / \mathrm{s}$. Using these definitions, the total 329 time spent walking and stationary in each of the zones of the arenas were recorded. The walking speed in each section was then calculated for each animal. When an animal was more than $5 \mathrm{~cm}$, or 1 average body length, from the wall it was considered to be in the open/away from the wall. An animal was considered

332 to be near the wall when it was within $5 \mathrm{~cm}$ of the wall. Climbing behavior was defined to have occurred when all walking legs of an individual were off the substrate and on at least one wall of the arena. When an animal climbed over the shelter but did not climb up onto a wall the behavior was not considered as 335 climbing. length from any angle of the food cap. When the crayfish was near the food source for more than 3 seconds, moving the maxillipeds and/or scraping the substratum with its chelae, the behavior was defined 339 as foraging. Before and after each trial the cap of fish gelatin was weighed to determine the amount of 340 food consumed by the crayfish. Shelter behavior was defined to have occurred when more than half of the 341 crayfish body was within the shelter. Near shelter behavior was defined as the crayfish being located 342 within one body length of the shelter and not in the shelter.

344 Many of the behaviors did not display significant differences between lesions and/or flowing 345 environments; therefore, we only reported the behaviors which showed significant differences between 346 the treatments (Table 1).

\section{Extraction of behaviors}



macro, which was created using excel. This macro provided the walking speed, time walking, time 350 stationary, and the total time crayfish spent in each of the three zones for all of the trials. The data was 351 then compiled into one table to be analyzed in R Studio.

\section{Statistical Analysis}

In order to assess the effect of sensory lesions, flowing environments, and the interaction of

354 sensory lesions and flowing environments on the detection of predators in crayfish, the behaviors stated 355 above were recorded and analyzed from the trial videos. Using the lme4 (Bates et al. 2015) and lmerTest 356 (Kuznetsova et al. 2015) packages in R statistical software v 3.3.1 (R Development Core Team 2016), 357 linear mixed models were used to determine the stated effects. Mixed models were chosen because stream 358 arenas were considered a random effect within the model. The models were developed using sensory 359 lesion (control, chemical active, visual active, and mechanical active) and environment (flowing or non360 flowing) as the fixed effects and the stream arenas $(1,2,3$, or 4$)$ as a random effect. Least squares means 361 post-hoc tests (difflsmeans) from the lmerTest package in R studio (Kuznetsova et al. 2015) were 362 conducted for each of the models.

\section{Results}

364 Significance of Lesions

365 Time in Zones

The differences between the lesion treatments significantly impacted the amount of time crayfish 367 spent in the threat zone of the arenas (Table 1). Chemical active animals spent significantly less time in 368 the threat zone of the arenas as compared to control animals (Table 2: LSM: $t=-2.66: p<0.05$ ). Control 369 and visual active animals spent significantly more time in the threat zone of the arenas than mechanical 370 active animals (Table 2: control vs. mechanical LSM: $t=3.88: p<0.05$; visual vs. mechanical LSM: $t=-$ 
$3712.23: p<0.05)$. The differences in lesions did not significantly impact the amount of time crayfish spent

372 in the resource or empty zones of the arenas (Table 2: Type II Wald Chi-square Test: $p>0.05$ ).

\section{Movement in Zones}

The movement of the crayfish throughout the arenas was also influenced by the differences in the

375 lesion combinations (Table 1). In the threat zone, both chemical active and mechanical active animals

376 walked significantly faster than control and visual active animals (Table 3: chemical vs. control LSM: $t$

$377=2.38: p<0.05$; chemical vs. visual LSM: $t=2.63: p<0.05$; mechanical vs. control LSM: $t=-4.15 ; p<$

3780.05 ; mechanical vs. visual LSM: $t=4.40: p<0.05$ ). However, there were no significant differences in

379 the amount of time crayfish spent stationary in the threat zone (Table 4: Type II Wald Chi-square Test: $p$

$380>0.05)$.

Significant differences were observed between the amount of time crayfish spent stationary in the resource zone of the arenas (Table 1: Type II Wald Chi-square Test: $p<0.05$ ); however, there were no significant differences in the walking speeds between the lesion groups in the resource zone (Type II

384 Wald Chi-square Test: $p>0.05$ ). Mechanical active and visual active animals remained stationary for longer periods of time as compared to control animals in the resource zone of the arenas (Table 4: mechanical vs. control LSM: $t=-3.83: p<0.05$; visual vs. control LSM: $t=-2.31: p<0.05$ ). Mechanical

387 active animals also spent significantly more time stopped in the resource zone than chemical active 388 animals (Table 4: LSM: $t=-2.38: p<0.05$ ). Although there were significant differences in the amount of 389 time crayfish spent in the resource zone, there were no significant differences in the time crayfish spent 390 near the food or shelter resources (Type II Wald Chi-square Test: $p>0.05$ ).

In the empty zone, mechanical active animals had significantly faster walking speeds than

392 control, chemical active, and visual active animals (Table 3: mechanical vs. control LSM: $t=-3.28: p<$

393 0.05; mechanical vs. chemical LSM: $t=-1.97: p<0.05$; mechanical vs. visual LSM: $t=3.64: p<0.05$ ). 
394 However, there were no significant differences in the amount of time crayfish spent stationary in the 395 empty zone between the lesion groups (Type II Wald Chi-square Test: $p>0.05$ ).

396 Significance of Flow

397 Time in Zones

There were no significant differences between the two environmental conditions in the total 399 duration crayfish spent in the fish, resource, and empty zones of the arenas (Type II Wald Chi-square $400 \quad$ Test: $p>0.05)$.

401

402

403

404

405

406

407

408

409

410

411

412

\section{Movement in Zones}

Crayfish in the threat zone of the flowing arenas had significantly faster walking speeds than crayfish in the non-flowing arenas (Tables 1,2: LSM: $t=2.02: p<0.05$ ). There were no significant differences in the amount of time crayfish remained stationary in the threat zone across both of the flowing environments (Table 4: Type II Wald Chi-square Test: $p>0.05$ ). There were no significant differences in the walking speed and the time crayfish remained stationary in the resource zones of both the flowing and non-flowing arenas (Type II Wald Chi-square Test: $p>0.05$ ). Crayfish had significantly faster walking speeds in the empty zone of the flowing arenas than crayfish in the non-flowing arenas (Table 3: LSM: $t=2.00: p<0.05$ ); however, there were no significant differences in the time crayfish spent stationary between the different flowing environments (Type II Wald Chi-square Test: $p<0.05$ ).

\section{Significance of the Interaction Between Lesion and Flow}

\section{Time in Zones}

Crayfish spent significantly different amounts of time in the resource zone of the arenas (Table 1:

Type II Wald Chi-square Test: $p<0.05$ ); however, the combined effect of both the lesions and the environments did not influence the time crayfish spent in the threat zone and empty zone of the arenas (Type II Wald Chi-square Test: $p>0.05$ ). In the resource zone of the flowing arenas chemical active, 
417 visual active, and mechanical active animals spent significantly more time in this zone than control 418 animals (Figure 3; Table 2; chemical flow vs. control flow LSM: $t=2.00: p<0.05$; visual flow vs. 419 control flow LSM: $t=-2.64: p<0.05$; mechanical flow vs. control flow LSM: $t=-2.71: p<0.05$ ). Visual 420 active animals in the flowing arenas remained in the resource zone for significantly longer periods of time 421 than visual active animals in the non-flowing arenas (Figure 3; Table 2; LSM: $t=2.48: p<0.05$ ). In the 422 non-flowing arenas, mechanical active animals spent significantly more time in the resource zone than 423 control, visual active, and chemical active animals (Figure 3; Table 2; mechanical no flow vs. control no

424 flow LSM: $t=-5.05: p<0.05$; mechanical no flow vs. visual no flow LSM: $t=3.95: p<0.05$;

425 mechanical no flow vs. chemical no flow LSM: $t=-3.44: p<0.05)$. Although there were significant 426 differences in the time crayfish spent in the resource zone, there were no significant differences in the 427 time the animals spent near the shelter or food cap (Type II Wald Chi-square Test: $p>0.05$ ).

\section{Movement in Zones} environments did not significantly influence the walking speeds of the crayfish in each of the zones of the arenas (Type II Wald Chi-square Test: $p>0.05$ ). In the threat zone of the flowing arenas, chemical active animals spent significantly less time stationary than control animals (Figure 4; Table 4; LSM: $t=-2.01: p$

$434<0.05)$. Chemical active animals in the non-flowing arenas spent significantly longer periods of time 435 stationary in the threat zone of the arenas than chemical active animals in the flowing arenas (Figure 4;

436 Table 4; LSM: $t=-2.90: p<0.05)$. In the threat zone of the non-flowing arenas, both control and 437 chemical active animals remained stationary for longer durations than mechanical active animals (Figure

4384 ; Table 4; mechanical no flow vs. control no flow LSM: $t=4.04: p<0.05$; chemical no flow vs.

439 mechanical no flow LSM: $t=3.13: p<0.05)$. However, mechanical active animals in the non-flowing 440 arenas spent significantly less time stationary in the threat zone than visual active animals (Figure 4;

441 Table 4; LSM: $t=-3.17: p<0.05)$. 
The interaction of the lesion and environment effect significantly impacted the amount of time

444 crayfish spent climbing the walls of the arenas (Figure 5; Tables 1,5; Type II Wald Chi-square Test: $p<$

445 0.05). In the flowing arenas, control animals spent significantly more time climbing the walls of the arena

446 than chemical active, visual active, and mechanical active animals (Figure 5; Table 5; control flow vs.

447 chemical flow LSM: $t=-2.47: p<0.05$; control flow vs. visual flow LSM: $t=2.44: p<0.05$; control

448 flow vs. mechanical flow LSM: $t=3.36: p<0.05)$. Control animals in the flowing arenas also spent

449 significantly more time climbing the walls than control animals in the non-flowing arenas (Figure 5;

450 Table 5; LSM: $t=2.25: p<0.05)$.

\section{Discussion}

The results from the study indicate the importance of sensory multimodality for predator detection. Specifically, behavior was significantly altered when crayfish were limited to only

454 chemoreception or mechanoreception. Limiting crayfish, a multimodal organism, to only one functional 455 sensory modality greatly inhibited the individual's ability to distinguish predatory stimuli in their 456 environment. Crayfish with only the full use of chemoreceptors (chemical active) or mechanoreceptors 457 (mechanical active) frequently walked around the arenas (Table 4) and had, on average, faster walking 458 speeds (Table 3). This may be indicative of an exploratory behavior that could serve to gather sensory 459 information about predator presence. Increased locomotor behavior will also increase the probability of 460 encountering a predator. The movement as opposed to stationary response of crayfish is dependent upon 461 the proximity of a shelter (Hazlett 1999). Conversely, visual active animals remained stationary for longer 462 periods of time throughout the trials (Table 4). Furthermore, the loss of chemical and/or mechanical 463 information in the visual active treatment appear to be to have the greatest impact on predator avoidance 464 as visual active (mechanical and chemical loss) animals remained closer to the predatory threat (Tables 2 , 
4). However, chemical active and mechanical active animals displayed opposite behaviors with remaining mobile and further from the predatory threat (Tables 2, 4).

The behaviors displayed by chemical active and mechanical active animals suggest that the

468 individuals were able to detect the predatory threat but could not accurately locate the source of the

469 stimulus. Whereas, visual active animals displayed behaviors which indicated they could efficiently locate

470 the predatory threat when near the source of the stimulus. The differences in behavior of the lesion

471 treatments (chemical active, visual active, and mechanical active) in this study indicate a hierarchy of

472 reliance in the modalities dependent upon the location of the animal within the sensory landscape. When

473 in close proximity to the predatory threat, crayfish rely upon the reception of visual cues to assess the

474 severity of the threat, followed by chemical and mechanical cues. However, when further from the

475 predatory threat, crayfish rely most heavily upon chemoreceptors followed by mechanoreceptors and

476 vision. Furthermore, crayfish whose sensory mechanisms were fully functional (control animals)

477 displayed more of an exploratory behavior, with more time climbing the walls of the arenas (Figure 5;

478 Table 5). These results demonstrate how the information from sensory systems can alter how predatory

479 cues influence behavior.

One of the important impacts of non-consumptive effects is alteration in resource use (Preisser et al. 2005; Laundré et al. 2010; Davenport et al. 2014). Although we did find some significant differences in the time spent in the resource area of our treatment, we did not find significant and consistent differences in shelter use among the different treatments. It appears as if the crayfish in this study spent a significant portion of their time in an increase state of vigilance. If so, this is time taken away from the search, acquisition, and use of potential resources. Despite the lack of differences in shelter use, the change in behavior from resource use to increase vigilance still demonstrates a significant non-

487 consumptive effect via sensory perception. A longer study and potentially more resources (such as localized food) might provide significant results as far as shelter use. 
predation and, as a result of the measurement of this threat, prey can alter their behavior in different ways.

491 For example, crayfish can determine not just the diet of a bass (chemical cues), but also the size or

492 swimming speed of the bass (visual cues), in which this information can be used to determine the severity

493 of the threat overall (Weissburg et al. 2014). Crabs (Heterozius rotundifrons [A. Milne-Edwards, 1867])

494 can determine a greater predatory threat through the reception of multiple signals, such as tactile

495 disturbances and chemical odors, and adjust their behavior accordingly (Hazlett and McLay 2005).

496 Sensory modalities most often provide unique information; however, some modalities can provide 497 redundant information (Partan and Marler 2005; Smith and Dunham 1990). For example, organisms can 498 detect the chemical cues released from an injured conspecific and the visual cues of a predator consuming 499 that conspecific, from integrating this information prey would be aware of a greater threat. This 500 redundancy in modalities could provide clearer information for the receiver of signals, especially when 501 considering environmental noise. Environmental noise is omnipresent; however, what might be noise for one modality might not be present for a second modality (Rubi and Stephens 2016; Troïanowksi et al.

503 2014).

Previous studies have shown that multiple species exhibit a 'multimodal shift', in that individuals 505 switch between modalities when one is limited in order to gather the most accurate information about 506 risks (Kraus-Epley et al. 2015; Troïanowksi et al. 2014). Differences in environmental conditions may

507 favor different modalities. A shift in sensory modality has been observed in adult three-spined stickleback 508 fishes, who most often rely on visual cues in clear waters but shift to chemical cues in turbid

509 environments (Troïanowksi et al 2014). Rabin et al. (2006) observed an increase on the reliance of visual 510 cues, rather than auditory cues, in California ground squirrels (Spermophilus beecheyi [Richardson, 511 1829]) in areas with higher auditory noise. In this study, changes in the external environment (flow) 512 caused the crayfish to reduce their reliance on chemical signals for sensory information. Crayfish under 513 these conditions relied more heavily upon visual and mechanical cues. Several studies recently have 
514 indicated the impact of additional environmental noise, pollutants (Callaghan et al. 2012; Lahman et al.

515 2015; McIntyre et al. 2008). McIntyre et al. (2008) found that environmentally relevant concentrations of 516 copper impaired the olfaction of juvenile coho salmon (Oncorhynchus kisutch). Therefore, shifts in

517 modalities might not just be occurring due to natural environmental noise, but human-created noise or the

518 presence of anthropogenic chemicals as well. Such shifts between modalities support the benefit of 519 multimodal communication.

The sensory landscape, within an organism's habitat, contains information on predators, prey, and conspecifics (Jurcak and Moore 2014). Prey are exposed to several predatory species including ambush and active hunters as well as benthic and more pelagic predators in aquatic environments or aerial and 523 ground hunters in terrestrial environments. These unique predators, coupled with their hunting modes, 524 create a diverse sensory landscape of fear (Preisser et al. 2005; Laundré et al. 2010; Davenport et al. 525 2014). On top of these predator landscapes, con- and heterospecifics create sensory signals and cues that 526 are important for the social and competitive behaviors of different organisms. For example, animals can 527 determine the sex, size, and social status of nearby conspecifics through the reception of cues and signals 528 (Acquistapace et al. 2002; Weissburg et al. 2014). The ability to recognize individuals, such as previous 529 opponents, from neighboring territories allows individuals to know whether to fight or flee (Crook et al. 530 2004). Injured conspecifics release alarm/chemical cues which alert nearby individuals of the presence of 531 a predatory threat (Elvidge and Brown 2012; Sih et al. 2010; Weiss et al. 2012). Prey species, or food 532 sources in general, create sensory cues and signals as well, alerting predators of a potential meal.

533 Individuals must effectively extract relevant information from the plethora of signals that are within their 534 sensory landscapes. The information extracted from sensory landscapes using multiple modalities determines prey behavior. In most literature, the alteration of prey behavior is placed under non-consumptive effects. The 537 behavioral (or physiological and morphological) responses to these sensory landscapes can dictate 538 ecological interactions like social behavior, size and location of foraging areas, and even territory sizes 
539 (Davenport and Chalcraft 2013; Elvidge and Brown 2015; Larsen 2012). Once an increased predatory

540 threat (detected through multiple modalities) is detected most species show a reduction in foraging and

541 mating behaviors and resort to predator avoidance behaviors, such as seeking shelter, fleeing, and/or

542 displaying a defensive stance (Smith and Belk 2001). Such antipredator responses result in energetic costs

543 which could lead to negative changes in the growth and survival rates of prey populations (Preisser et al.

544 2007). Subsequently, the interaction of prey sensory systems and the total sensory landscape of an

545 environment (not just predator signals) is what determines prey responses. Prey animals have different

546 sensory modalities as well as different thresholds of activation of those sensory modalities (Partan and

547 Marler 2005; Weissburg et al. 2014) which exhibit differing NCEs even within the same sensory

548 landscapes.

In order to fully comprehend the spatially and temporally dynamic nature of NCEs on prey

550 populations, an understanding of the sensory biology of organisms is needed (Sih et al. 2010; Weiss et al.

551 2012; Weissburg et al. 2014). Different habitats have unique sensory landscapes of predatory cues.

552 Furthermore, the interaction of the cues, their transmission through the environment, and prey's

553 sensitivity to those cues create the landscape of fear. Interacting with these different landscapes are prey

554 organisms with a variety of sensory modalities and sensitivities. As demonstrated here, changing the

555 sensitivity (such as lesioning) or the environmental transmission of stimuli (altering background flow)

556 alters the animal's detection and subsequent response to the presence of a predator. Thus, NCEs and

557 landscapes of fear need to incorporate the idea of different layers of landscape which depend upon several

558 factors including the sensory capabilities of the prey.

559 Acknowledgements

560 We thank the members of the Laboratory for Sensory Ecology for their reading of this manuscript,

561 assistance in the construction of the experimental arenas, and the collection of animals. We also thank the

562 University of Michigan Biological Station for the use of the Stream Research Facility and the funding of 
563 graduate research. The comments from two reviewers were essential in focusing the findings in this 564 paper.

\section{References}

566 Acquistapace, P., Aquiloni, L., Hazlett, B.A., and Gherardi, F. 2002. Multimodal communication in 567 crayfish: Sex recognition during mate search by male Austropotamobius pallipes. Can. J. Zool. 568 80(11): 2041-2045. doi:10.1139/Z02-171.

Bates, D., Machler, M., Bolker, B.M., and Walker, S.C. 2015. Fitting linear mixed-effects models using lme4. J. of Stat. Soft. 67(1): 1-48. doi:10.18637/jss.v067.i01.

571

572

573

574

575

576

577

578

579

580

581

582

583

584

Belgane, P.F., Grasso, F.W., Basil, J.A., and Atema, J. 1997. Far field chemo-orientation in the American lobster, Homarus americanus: Effects of unilateral ablation and lesioning of the lateral antennule. Biol. Bull. 193(2): 214-215.

Bergman, D.A., Redman, C.N., Fero, K.C., Simon, J.L., and Moore, P.A. 2006. The impacts of flow on chemical communication strategies and fight dynamics of crayfish. Mar. Freshw. Behav. Phys. 39(4): 245-258. doi:10.1080/10236240600980608.

Bouskila, A. 1995. Interactions between predation risk and competition: A field study of kangaroo rats and snakes. Ecol. 76(1): 165-178. doi:10.2307/1940639.

Cabido, C., Gonzalo, A., Galán, P., Martín, J., and López, P. 2004. Chemosensory predator recognition induces defensive behavior in slow worm (Anguis fragilis). Can. J. Zool. 82(3): 510-515. doi:10.1139/z04-023.

Callaghan, D.T., Dew, W.A., Weisbord, C.D., and Pyle, G.G. 2012. The role of various sensory inputs in establishing social hierarchies in crayfish. Behav. 149(13-14): 1443-1458. doi:10.1163/1568539X-00003033. 
585

586

587

588

589

590

591

592

593

594

595

596

597

598

599

600

601

602

603

604

605

606

607

Crook, R., Patullo, B.W., and MacMillan, D.L. 2004. Multimodal individual recognition in the crayfish Cherax destructor. Mar. Freshw. Behav. Phys. 37(4): 271-285. doi:10.1080/10236240400016595.

Davenport, J.M., and Chalcraft, D.R. 2013. Nonconsumptive effects in a multiple predator system reduce the foraging efficiency of a keystone predator. Ecol. Evol. 3(9): 3063-3072. doi:10.1002/ece3.691.

Davenport, J.M., Hossack, B.R., and Lowe, W.H. 2014. Partitioning the non-consumptive effects of predators on prey with complex life histories. Oecol. 176(1):149-155. doi: 10.1007/s00442-0142996-5.

Dzialowski, A.R., Lennon, J.T., O’Brien, W.J., and Smith, V.H. 2003. Predator-induced phenotypic plasticity in the exotic cladoceran Daphnia lumholtzi. Freshw. Biol. 48(9): 1593-1602. doi:10.1046/j.1365-2427.2003.01111.x.

Elvidge, C.K., and Brown, G.E. 2012. Visual and chemical prey cues as complementary predator attractants in a tropical stream fish assemblage. Intern. J. of Zool. 2012: 1-7. doi:10.1155/2012/510920.

Elvidge, C.K., and Brown, G.E. 2015. Nonconsumptive effects of predation and impaired chemosensory risk assessment on an aquatic prey species. Intern. J. of Ecol. 2015: 1-9. doi:10.1155/2015/894579.

Fine M.L., Mayo, M.S., Newton, S.H., and Sismour, E.N. 2011. Largemouth bass predators reduce growth, feeding and movement in juvenile channel catfish. Ecol. Freshw. Fish, 20(1): 114-119. doi:10.1111/j.1600-0633.2010.00466.x.

Hazlett, B.A. 1999. Responses to multiple chemical cues by the crayfish Orconectes virilis. Behav. 136(2):161-177. doi: 10.1163/156853999501261 
608

609

610

611

612

613

614

615

616

617

618

619

620

621

622

623

624

625

626

627

628

629

Hazlett, B.A., and McLay, C. 2005. Responses to predation risk: alternative strategies in the crab Heterozius rotundifrons. Anim. Behav. 69(4): 967-972. doi:10.1016/j.anbehav.2004.06.028

Hazlett, B.A., Acquistapace, P., and Gherardi, F. 2006. Responses of the crayfish Orconectes virilis to chemical cues depend on flow conditions. J. of Crust. Biol. 26(1): 94-98. doi:10.1651/C-2595.1.

Jurcak, A.M., and Moore, P.A. 2014. Behavioral decisions in sensory landscapes: Crayfish use chemical signals to make habitat use choices. J. of Crust. Biol. 34(5): 559-564. doi:10.1163/1937240X00002266.

Karavanich, C., and Atema, J. 1998. Individual recognition and memory in lobster dominance. Anim. Behav. 56(6): 1553-1560. doi:10.1006/anbe.1998.0914.

Keller, T.A., and Moore, P.A. 2000. Context-specific behavior: Crayfish size influences crayfish-fish interactions. J. N. Am. Benthol. S. 19(2): 344-351. doi:10.2307/1468076.

Kraus - Epley, K.E., and Moore, P.A. 2002. Bilateral and unilateral antennal lesions alter orientation abilities of the crayfish, Orconectes rusticus. Chem. Sen. 27(1): 49-55.

Kraus - Epley, K.E., Lahman, S.E., Moore, P.A. 2015. Behaviorally-selective chemoreceptor lesions reveal two different chemically mediated orientation strategies in the rusty crayfish, Orconectes rusticus. J. of Crust. Biol. 35(6): 753-762. doi:10.1163/1937240X-00002378.

Kuznestova, A., P. Brockhoff, and R. Christenesen. 2015. Package lmerTest R package version 2.

Lahman, S.E., Trent, K.R., and Moore, P.A. 2015. Sublethal copper toxicity impairs chemical orientation in the crayfish, Orconectes rusticus. Ecotox. Environ. Safe. 113(2015): 369-377. doi:10.1016/j.ecoenv.2014.12.022.

Larsen, A.E. 2012. Modeling multiple nonconsumptive effects in simple food webs: a modified LotkaVolterra approach. Behav. Ecol. 23(5): 1115-1125. doi:10.1093/beheco/ars081. 
630

631

632 633

634

635

636

637

638

639

640

641

642

643

644

645

646

647

648

649

650

Laundré, J.W., Hernández, L., and Ripple, W.J. 2010. The landscape of fear: Ecological implications of being afraid. Open Ecol. J. 3(2): 1-7. doi:10.2174/1874213001003030001.

Lima, S.L., and Dill, L.M. 1990. Behavioral decisions made under the risk of predation: a review and prospectus. Can. J. Zool. 68(4): 619-640. doi:10.1139/z90-092.

Lohrey, A.K., Clark, D.L., Gordon, S.D., and Uetz, G.W. 2009. Antipredator responses of wolf spiders (Araneae: Lycosidae) to sensory cues representing an avian predator. Anim. Behav. 77(4): 813821. doi:10.1016/j.anbehav.2008.12.025.

Lunt, J., and Smee, D.L. 2015. Turbidity interferes with foraging success of visual but not chemosensory predators. PeerJ, 3(9): e1212. doi:10.7717/peerj.1212.

McIntyre, J.K., Baldwin, D.H., Meador, J.P., and Scholz, N.L. 2008. Chemosensory deprivation in juvenile coho salmon exposed to dissolved copper under varying water chemistry conditions. Environ. Sci. Tech. 42(4): 1352-1358. doi:10.1021/es071603e.

Moore, P.A., and Grills, J.L. 1999. Chemical orientation to food by the crayfish Orconectes rusticus: influence of hydrodynamics. Anim. Behav. 58(5): 953-963. doi:10.1006/anbe.1999.1230.

Moore, P.A., Ferrante, P.A., and Bergner, J.L. 2015. Chemical orientation strategies of the crayfish are influenced by the hydrodynamics of their native environment. The Amer. Mid. Nat. 173(1):17-29. doi:10.1674/0003-0031-173.1.17.

Partan, S.R., and Marler, P. 2005. Issues in the classification of multimodal communication signals. The Am. Nat. 166(2): 231-245. doi:10.1086/431246.

Preisser, E.L., Bolnick, D.I., and Benard, M.E. 2005. Scared to death? The effects of intimidation and consumption in predator-prey interactions. Ecol. 86(2): 501-509. doi:10.1890/04-0719. 
651 Preisser, E.L., Orrock, J.L., and Schmitz, O.J. 2007. Predator hunting mode and habitat domain alter nonconsumptive effects in predator-prey interactions. Ecol. 88(11): 2744-2751. doi:10.1890/070260.1 .

654 655 656 657 658 659 660 661 662 663 664 665 666 667 668 669 670 671 672 673

Rabin, L.A., Coss, R.G., Owings, D.H. 2006. The effects of wind turbines on antipredator behavior in California ground squirrels (Spermophilus beecheyi). Biol. Con. 131(3): 410-420. doi:10.1016/j.biocon.2006.02.016.

Rapin, K. and Moore, P.A. 2016. Do laboratory syndromes predict field behavior? Comparison of laboratory based syndromes and field based measurements. M.S. thesis, Department of Biology, Bowling Green State University, Bowling Green, $\mathrm{OH}$.

R Core Team, 2016. R: A language and environment for statistical computing. R Foundation for Statistical computing, Vienna, Austria. URL https://www.R-project.org/.

Rendon, D., Whitehouse, M.E.A., and Taylor, P.W. 2015. Consumptive and non-consumptive effects of wolf spiders on cotton bollworms. Entomol. Exper. App. 158(2): 170-183. doi:10.1111/eea.12390.

Ripple, W.J., and Beschta, R.L. 2006. Linking wolves to willows via risk-sensitive foraging by ungulates in the northern Yellowstone ecosystem. For. Ecol. Man. 230(1): 96-106. doi:10.1016/j.foreco.2006.04.023.

Rubi, T.L., and Stephens, D.W. 2016. Does multimodality per se improve receiver performance? An explicit comparison of multimodal versus unimodal complex signals in a learned signal following task. Behav. Ecol.Sociobio. 70(3): 409-416. doi:10.1007/s00265-016-2061-y.

Sih, A., Bolnick, D.I., Luttbeg, B., Orrock, J.L., Peacor, S.D., Pintor, L.M., Preisser, E., Rehage, J.S., and Vonesh, J.R. 2010. Predator - prey naïveté, antipredator behavior, and the ecology of predator invasions. OIKOS, 119(4): 610-621. doi:10.1111/j.1600-0706.2009.18039.x. 
674 Smith, M.R., and Dunham, D.W. 1990. Chela posture and vision: Compensation for sensory deficit in the

675

676 677

678

679 680

681

682

683

684

685

686

687

688

689

690

691

692

693

694

695 crayfish Orconectes propinquus. Crust. 59(3): 309-313. doi:10.1163/156854090X00552.

Smith, M.E., and Belk, M.C. 2001. Risk assessment in western mosquitofish (Gambusia affinis): Do multiple cues have additive effects? Behav. Ecol. Sociobio. 51(1): 101-107. doi:10.1007/s002650100415.

Troïanowski, M., Melot, G., and Lengagne, T. 2014. Multimodality: A way to cope with road traffic noise? The case of European treefrog (Hyla arborea). Behavi. Pro. 107(2014): 88-93. doi:10.1016/j.beproc.2014.07.007.

Turner, A. and Peacor, S. 2012. Scaling up infochemicals: ecological consequences of chemosensory assessment of predation risk. In Chemical Ecology in Aquatic Systems. Edited by C. Brönmark and L. Hansson. Oxford University Press, Oxford. pp. 140-157.

Weiss, L., Laforsch, C., and Tollrian, R. 2012. The taste of predation and the defenses of prey. In Chemical Ecology in Aquatic Systems. Edited by C. Brönmark and L. Hansson. Oxford University Press, Oxford. pp. 111-126.

Weissburg, M. 2012. Death from downstream: chemosensory navigation and predator-prey processes. In Chemical Ecology in Aquatic Systems. Edited by C. Brönmark and L. Hansson. Oxford University Press, Oxford. pp. 96-110.

Weissburg, M., Smee, D.L., and Ferner, M.C. 2014. The sensory ecology of nonconsumptive predator effects. The Am. Nat. 184(2): 141-157. doi:10.1086/676644.

Wolf, M.C., Voigt, R., and Moore, P.A. 2004. Spatial arrangement of odor sources modifies the temporal aspects of crayfish search strategies. J. Chem. Ecol. 30(3): 501-517. doi:10.1023/B:JOEC.0000018625.83906.95. 
696 Wolf, M.C., Martin, A.L., Simon, J.L., Bergner, J.L., and Moore, P.A. 2009. Chemosensory signals in 697 stream habitats: implications for ecological interactions. J. N. Am. Benthol. S. 28(3): 560-571. doi:10.1899/08-108.1. 
Table 1. Significant differences of behavior observed in rusty crayfish (Orconectes rusticus) when considering the main statistical effects (Lesion and Flow) and the interaction effect (Lesion:Flow; Type II Wald Chi-square Tests, LSM post-hoc, $p<0.05)$.

\begin{tabular}{|l|c|c|c|}
\hline \multicolumn{1}{|c|}{ Response } & Effect & $\boldsymbol{F}$ Value & $\boldsymbol{P}$ Value \\
\hline Time in Fish Zone & Main: Lesion & $\boldsymbol{F}_{(3,77,0.05)}=16.1540$ & 0.001054 \\
\hline Walking Speed in Fish Zone & Main: Lesion & $\boldsymbol{F}_{(3,77,0.05)}=26.1386$ & 0.000008 \\
\hline Time Stopped in Resource Zone & Main: Lesion & $\boldsymbol{F}_{(3,77,0.05)}=15.4057$ & 0.001501 \\
\hline Time Walking in Resource Zone & Main: Lesion & $\boldsymbol{F}_{(3,77,0.05)}=42.6780$ & $2.88 \mathrm{e}-09$ \\
\hline Time Walking in Empty Zone & Main: Lesion & $\boldsymbol{F}_{(3,77,0.05)}=8.6601$ & 0.03417 \\
\hline Walking Speed in Empty Zone & Main: Lesion & $\boldsymbol{F}_{(3,77,0.05)}=16.3057$ & 0.000981 \\
\hline Time Against the Walls & Main: Lesion & $\boldsymbol{F}_{(3,77,0.05)}=46.0455$ & $5.54 \mathrm{e}-10$ \\
\hline Time Away from the Walls & Main: Lesion & $\boldsymbol{F}_{(3,77,0.05)}=46.0586$ & $5.51 \mathrm{e}-10$ \\
\hline Time Walking in Fish Zone & Main: Flow & $\boldsymbol{F}_{(1,79,0.05)}=5.4640$ & 0.01941 \\
\hline Walking Speed in Fish Zone & Main: Flow & $\boldsymbol{F}_{(1,79,0.05)}=4.0818$ & 0.04335 \\
\hline Time Walking in Resource Zone & Main: Flow & $\boldsymbol{F}_{(1,79,0.05)}=9.7931$ & 0.001752 \\
\hline Walking Speed in Empty Zone & Main: Flow & $\boldsymbol{F}_{(1,79,0.05)}=3.9997$ & 0.045507 \\
\hline Time Stopped in Fish Zone & Interaction & $\boldsymbol{F}_{(7,73,0.05)}=10.3349$ & 0.015923 \\
\hline Time in Resource Zone & Interaction & $\boldsymbol{F}_{(7,73,0.05)}=0.04684$ & 0.04684 \\
\hline Time Climbing the Walls & Interaction & $\boldsymbol{F}_{(7,73,0.05)}=8.8976$ & 0.03068 \\
\hline
\end{tabular}


Table 2. Mean ( \pm SEM) time ( $s$ ) rusty crayfish (Orconectes rusticus) remained in the fish, resource, and empty zones of both the flowing and non-flowing arenas. In the interaction effect section of the table, variables with the same letter are significantly different from each other for time spent in the resource zone. This was the only variable in this table that produced statistically significant effects.

\begin{tabular}{|c|c|c|c|c|}
\hline & & $\begin{array}{l}\text { Fish } \\
\text { Zone }\end{array}$ & $\begin{array}{l}\text { Resource } \\
\text { Zone }\end{array}$ & $\begin{array}{l}\text { Empty } \\
\text { Zone }\end{array}$ \\
\hline \multirow{4}{*}{$\begin{array}{l}\text { Lesion } \\
\text { Effect }\end{array}$} & Control & $1181 \pm 104$ & $228 \pm 63.8$ & $388 \pm 89.8$ \\
\hline & Chemical Active & $818 \pm 113$ & $512 \pm 72.5$ & $467 \pm 80.4$ \\
\hline & Visual Active & $956 \pm 106$ & $530 \pm 111$ & $312 \pm 52.9$ \\
\hline & Mechanical Active & $652 \pm 88.8$ & $849 \pm 98.6$ & $297 \pm 51.7$ \\
\hline \multirow{2}{*}{$\begin{array}{l}\text { Flow } \\
\text { Effect }\end{array}$} & Flowing Arenas & $864 \pm 72.6$ & $595 \pm 70.0$ & $338 \pm 43.0$ \\
\hline & Non - Flowing Arenas & $940 \pm 84.0$ & $464 \pm 70.7$ & $393 \pm 56.8$ \\
\hline \multirow{8}{*}{$\begin{array}{c}\text { Interaction } \\
\text { Effect }\end{array}$} & Flowing Control $(\mathrm{B}, \mathrm{G}, \mathrm{K})$ & $1129 \pm 120$ & $302 \pm 118$ & $365 \pm 93.2$ \\
\hline & Flowing Chemical Active (E) & $706 \pm 124$ & $616 \pm 94.3$ & $476 \pm 86.5$ \\
\hline & Flowing Visual Active (I, J, K) & $801 \pm 183$ & $728 \pm 184$ & $269 \pm 77.2$ \\
\hline & Flowing Mechanical Active $(F, G, H)$ & $819 \pm 128$ & $735 \pm 119$ & $243 \pm 78.7$ \\
\hline & Non - Flowing Control (A, F, I) & $1233 \pm 175$ & $155 \pm 43.7$ & $410 \pm 158$ \\
\hline & Non - Flowing Chemical Active (D) & $931 \pm 190$ & $409 \pm 104$ & $458 \pm 140$ \\
\hline & $\begin{array}{l}\text { Non - Flowing Visual Active }(\mathrm{C}, \mathrm{H} \text {, } \\
\mathrm{J})\end{array}$ & $1111 \pm 93.4$ & $331 \pm 96.6$ & $355 \pm 73.8$ \\
\hline & $\begin{array}{l}\text { Non - Flowing Mechanical Active } \\
(A, B, C, D, E)\end{array}$ & $484 \pm 102$ & $963 \pm 154$ & $350 \pm 66.6$ \\
\hline
\end{tabular}


Table 3. Mean ( \pm SEM) walking speed $(\mathrm{cm} / \mathrm{s})$ of rusty crayfish (Orconectes rusticus) in the fish, resource, and empty zones of both the flowing and non-flowing arenas. In the main effect sections of the table, variables with the same letter are significantly different from each other for walking speed. With the lesion effect, the significant differences were identical for the fish and empty zones.

\begin{tabular}{|c|l|c|c|c|}
\cline { 3 - 4 } \multicolumn{2}{c|}{} & \multicolumn{1}{c|}{$\begin{array}{c}\text { Fish } \\
\text { Zone }\end{array}$} & $\begin{array}{c}\text { Resource } \\
\text { Zone }\end{array}$ & $\begin{array}{c}\text { Empty } \\
\text { Zone }\end{array}$ \\
\hline \multirow{4}{*}{$\begin{array}{c}\text { Lesion } \\
\text { Effect }\end{array}$} & Control (B, E) & $0.61 \pm 0.06$ & $1.11 \pm 0.13$ & $0.93 \pm 0.15$ \\
\cline { 2 - 5 } & Chemical Active (C, D,E) & $1.10 \pm 0.17$ & $1.16 \pm 0.23$ & $1.33 \pm 0.25$ \\
\cline { 2 - 5 } & Visual Active (A, D) & $0.56 \pm 0.08$ & $0.90 \pm 0.19$ & $0.82 \pm 0.13$ \\
\cline { 2 - 5 } & Mechanical Active (A, B, C) & $1.47 \pm 0.24$ & $1.17 \pm 0.27$ & $1.92 \pm 0.32$ \\
\hline \multirow{3}{*}{$\begin{array}{c}\text { Flow } \\
\text { Effect }\end{array}$} & Flowing Arenas & $1.08 \pm 0.14$ & $1.16 \pm 0.16$ & $1.47 \pm 0.20$ \\
\cline { 2 - 5 } & Non - Flowing Arenas & $0.79 \pm 0.10$ & $1.01 \pm 0.13$ & $1.04 \pm 0.14$ \\
\hline \multirow{4}{*}{$\begin{array}{c}\text { Interaction } \\
\text { Effect }\end{array}$} & Flowing Control & $0.66 \pm 0.03$ & $1.18 \pm 0.18$ & $0.93 \pm 0.18$ \\
\cline { 2 - 5 } & Flowing Chemical Active & $1.47 \pm 0.23$ & $1.39 \pm 0.36$ & $1.77 \pm 0.38$ \\
\cline { 2 - 5 } & Flowing Visual Active & $0.57 \pm 0.10$ & $0.66 \pm 0.20$ & $0.88 \pm 0.24$ \\
\cline { 2 - 5 } & Flowing Mechanical Active & $1.63 \pm 0.41$ & $1.39 \pm 0.43$ & $2.28 \pm 0.55$ \\
\cline { 2 - 5 } & Non- Flowing Control & $0.56 \pm 0.12$ & $1.04 \pm 0.18$ & $0.93 \pm 0.25$ \\
\cline { 2 - 5 } & Non - Flowing Chemical Active & $0.74 \pm 0.20$ & $0.93 \pm 0.28$ & $0.89 \pm 0.29$ \\
\cline { 2 - 5 } & Non - Flowing Visual Active & $0.55 \pm 0.12$ & $1.14 \pm 0.31$ & $0.77 \pm 0.14$ \\
\cline { 2 - 5 } & Non - Flowing Mechanical Active & $1.30 \pm 0.27$ & $0.95 \pm 0.31$ & $1.57 \pm 0.33$ \\
\hline
\end{tabular}

712 
Table 4. Mean ( \pm SEM) time (s) rusty crayfish (Orconectes rusticus) remained stationary in the fish, resource, and empty zones of both the flowing and non-flowing arenas. In the main effect (resource zone) and interaction effect (fish zone) section of the table, variables with the same letter are significantly different from each other.

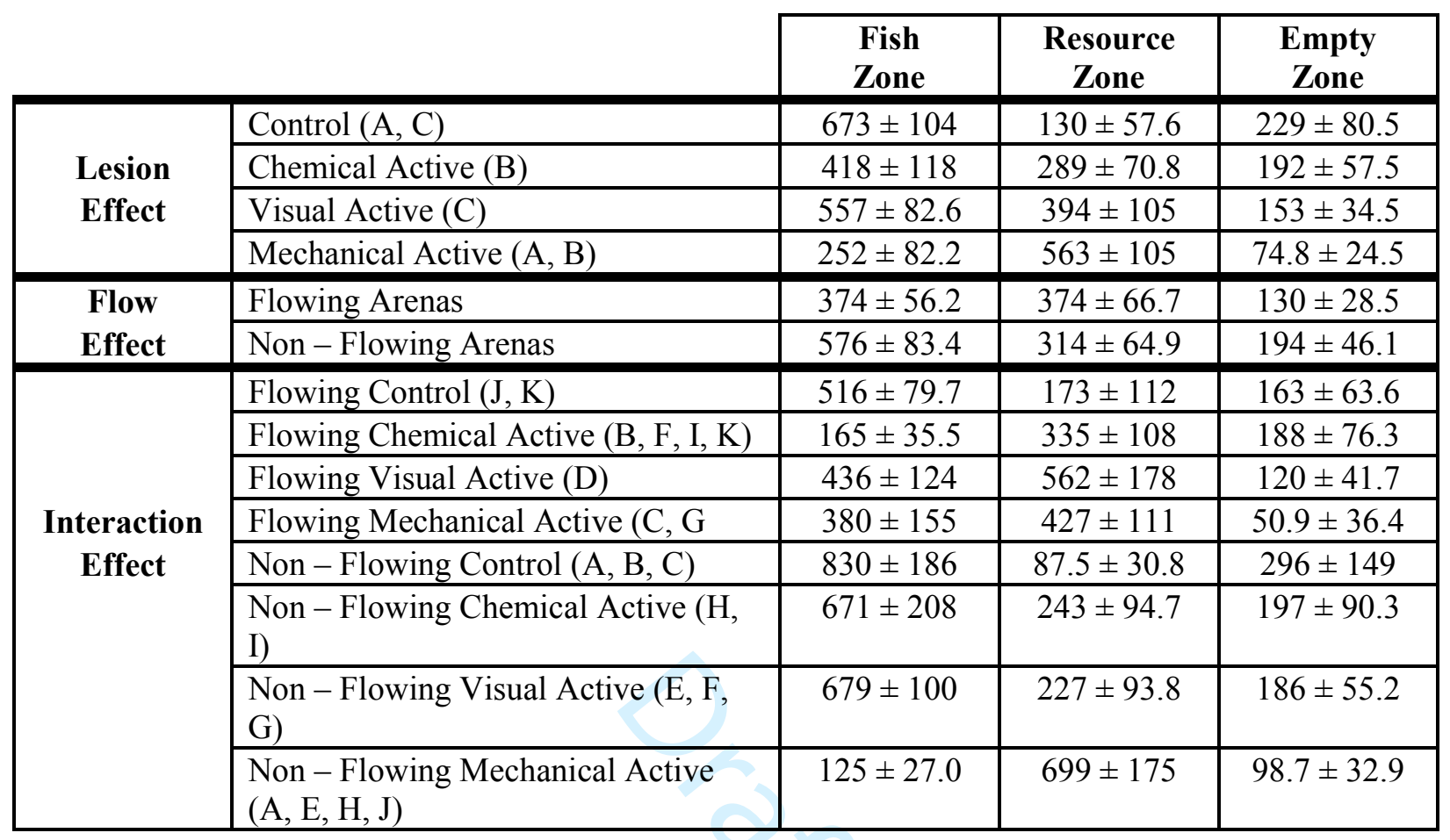


718 Table 5. Mean ( \pm SEM) time (s) rusty crayfish (Orconectes rusticus) spent climbing the walls of both the 719 flowing and non-flowing arenas.

\begin{tabular}{|c|l|c|}
\cline { 3 - 3 } Lesion \\
Effect & Control & Time Climbing (s) \\
\cline { 2 - 3 } & Chemical Active & $234.8 \pm 47.1$ \\
\cline { 2 - 3 } & Visual Active & $157.5 \pm 83.2$ \\
\cline { 2 - 3 } Flow & Mechanical Active & $179.5 \pm 49.4$ \\
\hline \multirow{4}{*}{$\begin{array}{c}\text { Effect } \\
\text { Enteraction }\end{array}$} & Flowing Arenas & $53.8 \pm 18.1$ \\
\cline { 2 - 3 } & Non - Flowing Arenas & $155 \pm 30.5$ \\
\hline & Flowing Control & $157.8 \pm 46.8$ \\
\cline { 2 - 3 } & Flowing Chemical Active & $361.3 \pm 59.9$ \\
\cline { 2 - 3 } & Flowing Visual Active & $115.3 \pm 43.8$ \\
\cline { 2 - 3 } & Nowing Mechanical Active & $118 \pm 60.1$ \\
\cline { 2 - 3 } & Non - Flowing Control & $25.5 \pm 9.4$ \\
\cline { 2 - 3 } & Non - Flowing Chemical Active & $108.4 \pm 47.3$ \\
\cline { 2 - 3 } & Non - Flowing Visual Active & $241 \pm 76.4$ \\
\cline { 2 - 3 } & & $82.2 \pm 33.5$ \\
\hline
\end{tabular}


722 Figure 1. For the visual lesions and sham lesions two sizes of tear-shaped goggles were created by using 723 Sylgard $₫ 184$ Silicone Elastomer for clear goggles and Sylgard $₫ 170$ Silicone Elastomer for black 724 goggles. (1A) Small goggles $(1.8 \mathrm{~cm} \times 1.3 \mathrm{~cm} \mathrm{~L}: \mathrm{W})$ consisted of a $5 \mathrm{~mm}$ indentation which covered the 725 eyes of the rusty crayfish (Orconectes rusticus) without hindering the movement of the eyes/eye stalks. 726 (1B) Large goggles $(2.5 \mathrm{~cm} \times 1.8 \mathrm{~cm} \mathrm{~L}: W)$ consisted of a $7 \mathrm{~mm}$ indentation which covered the eyes of the 727 rusty crayfish without hindering the movement of the eyes/eye stalks.

728 Figure 2. Four identical experimental arenas $(121 \mathrm{~cm}$ x $81 \mathrm{~cm} \mathrm{~L}: \mathrm{W})$ were constructed with the use of cinderblocks lined with plastic sheeting. An egg crating divider was placed within the arenas to prevent physical interactions between the rusty crayfish (Orconectes rusticus) and largemouth bass (Micropterus salmoides). For the flowing arenas, water from the Maple River filled headtanks in which hoses supplied water to the upstream area of the arenas. The water then flowed through the arena and exited the opposite end through an outflow board. During acclimation, a secondary input and output of water were placed, along with a non-porous divider, to allow both the rusty crayfish and largemouth bass to simultaneously acclimate to the flowing condition without the mixture of stimuli. The secondary input and output of water as well as the non-porous divider were removed after acclimation. For the non-flowing arenas, there were no input or output of water throughout both the acclimation and trial periods.

Figure 3. Mean ( \pm SEM) time (s) rusty crayfish (Orconectes rusticus) spent in the resource zone of the flowing and non-flowing arenas when considering the interaction of the main statistical effects (Lesion and Flow; Type II Wald Chi-square Tests, LSM post-hoc, $p<0.05)$. The differences in symbols represent the lesions: control animals (square), chemical active animals (circle), visual active animals (triangle), and mechanical active animals (diamond). Pairwise significant differences can be found in table 3 .

Figure 4. Mean ( \pm SEM) time (s) rusty crayfish (Orconectes rusticus) spent stationary in the fish zone of the flowing and non-flowing arenas when considering the interaction of the main statistical effects (Lesion and Flow; Type II Wald Chi-square Tests, LSM post-hoc, $p<0.05$ ). The differences in symbols represent the lesions: control animals (square), chemical active animals (circle), visual active animals (triangle), and mechanical active animals (diamond). Pairwise significant differences can be found in table 4.

Figure 5. Mean ( \pm SEM) time (s) rusty crayfish (Orconectes rusticus) spent climbing the walls of the flowing and non-flowing arenas when considering the interaction of the main statistical effects (Lesion and Flow; Type II Wald Chi-square Tests, LSM post-hoc, $p<0.05)$. The differences in symbols represent the lesions: control animals (square), chemical active animals (circle), visual active animals (triangle), and mechanical active animals (diamond). 
1 A.

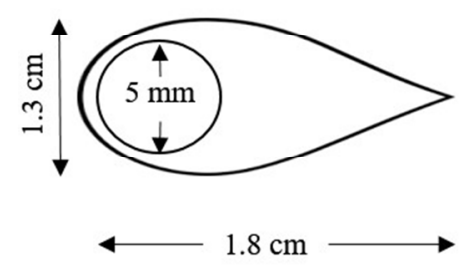

$1 B$.

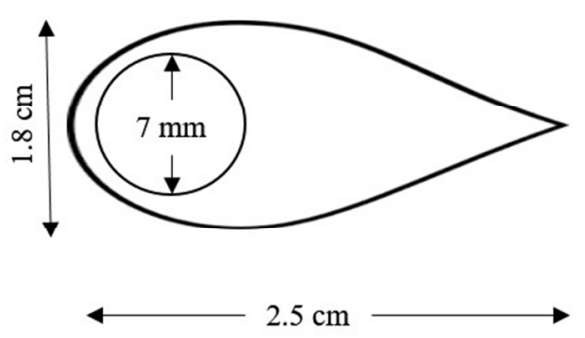

Figure 1 257x73mm (96 x 96 DPI) 


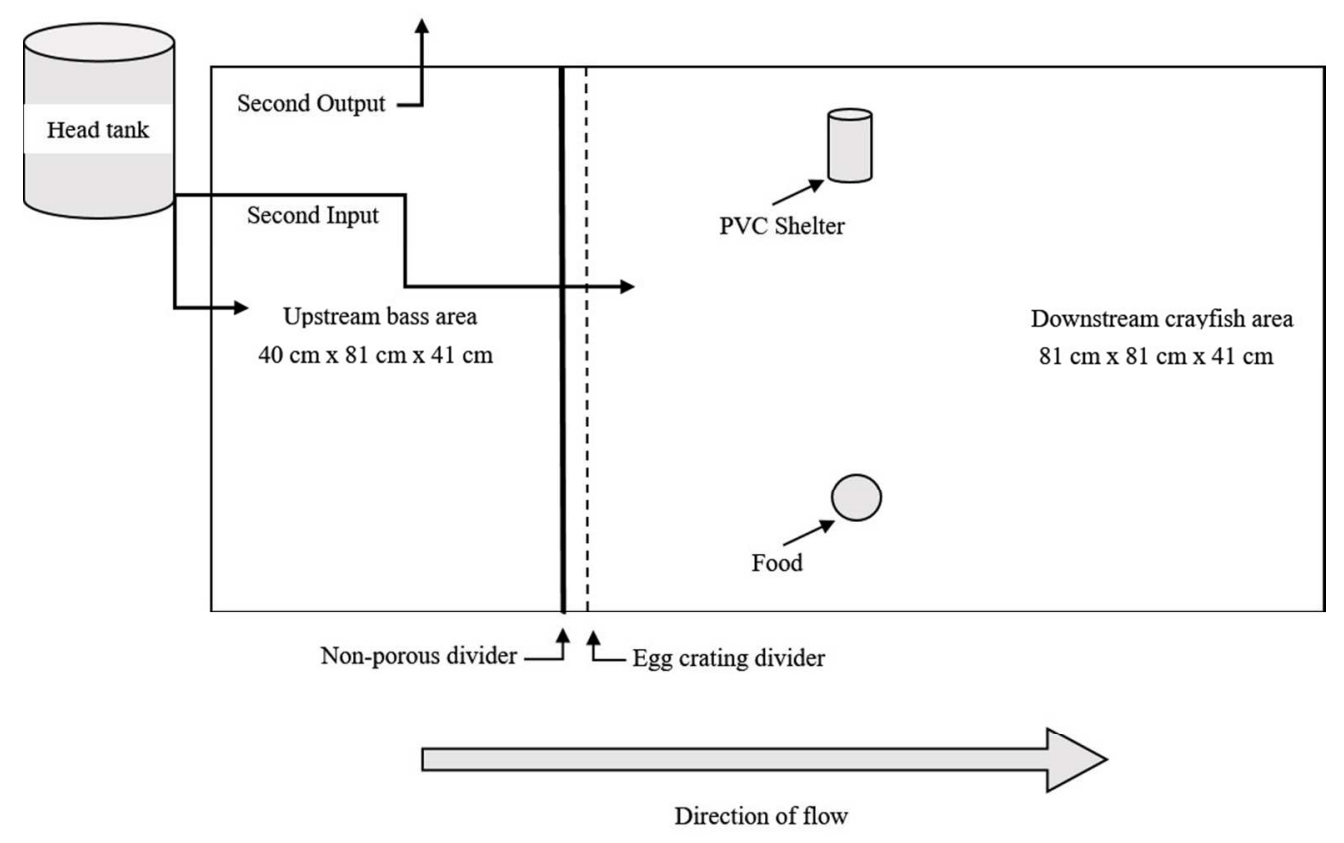

Figure 2

$288 \times 188 \mathrm{~mm}(96 \times 96 \mathrm{DPI})$ 


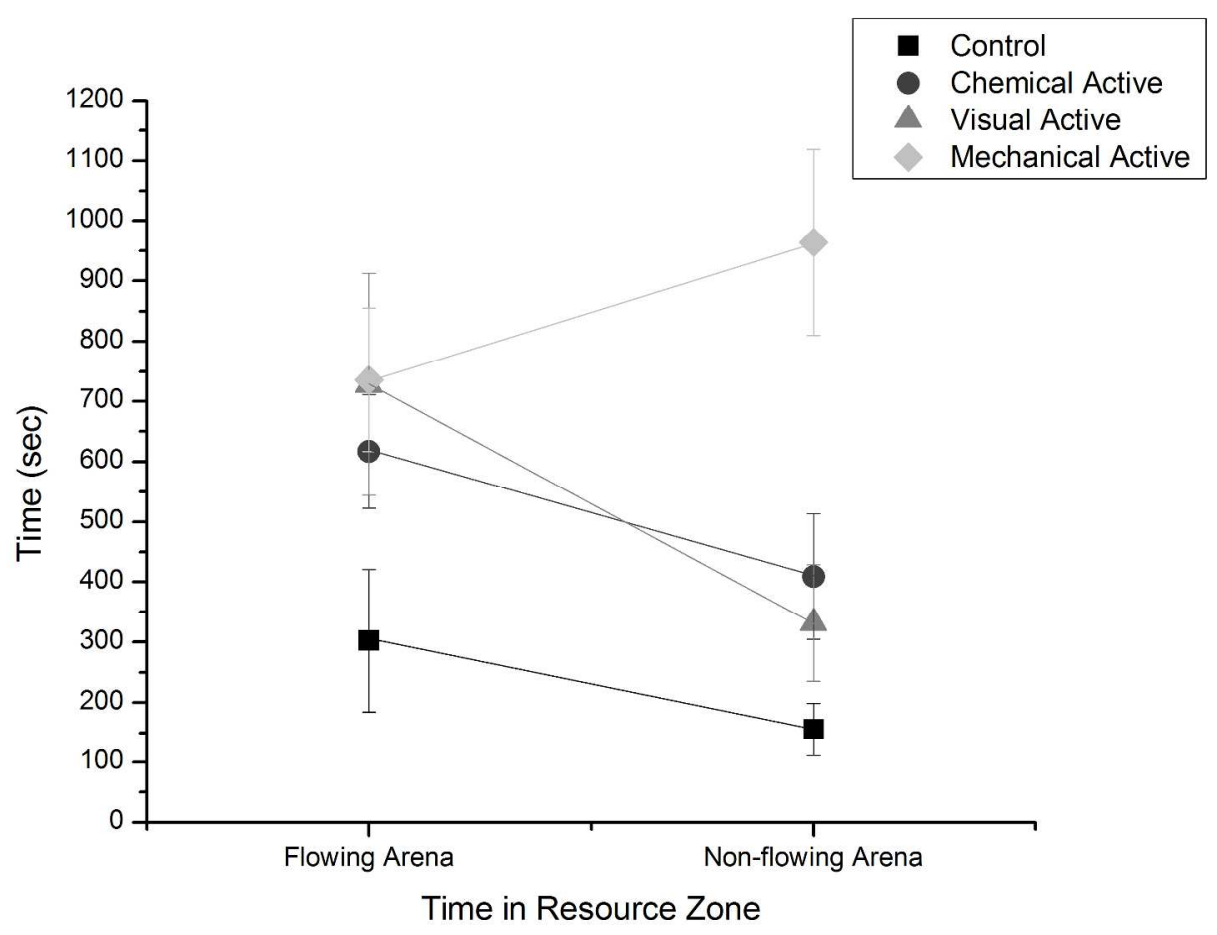

Figure 3

$279 \times 215 \mathrm{~mm}(300 \times 300 \mathrm{DPI})$ 


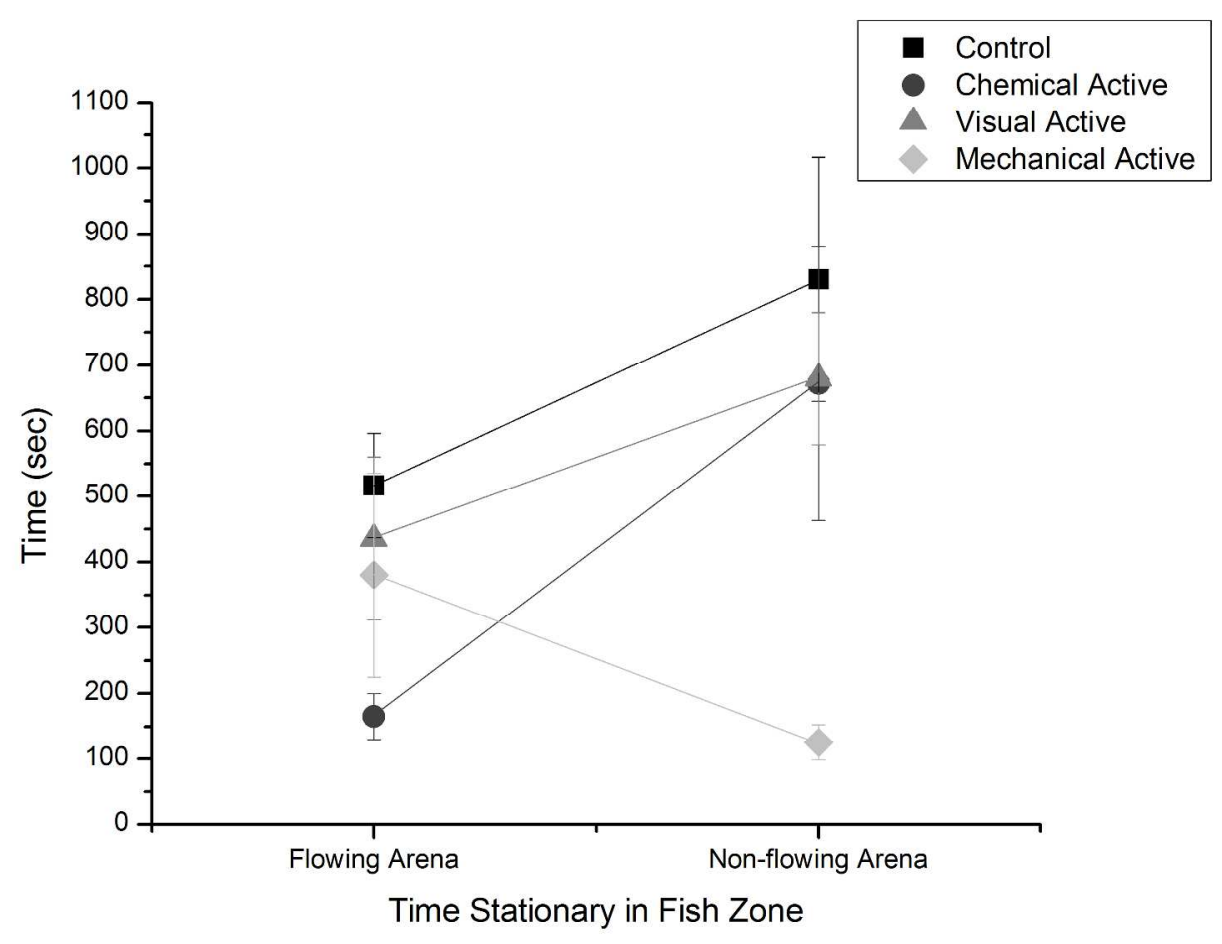

Figure 4

$279 \times 215 \mathrm{~mm}(300 \times 300$ DPI $)$ 


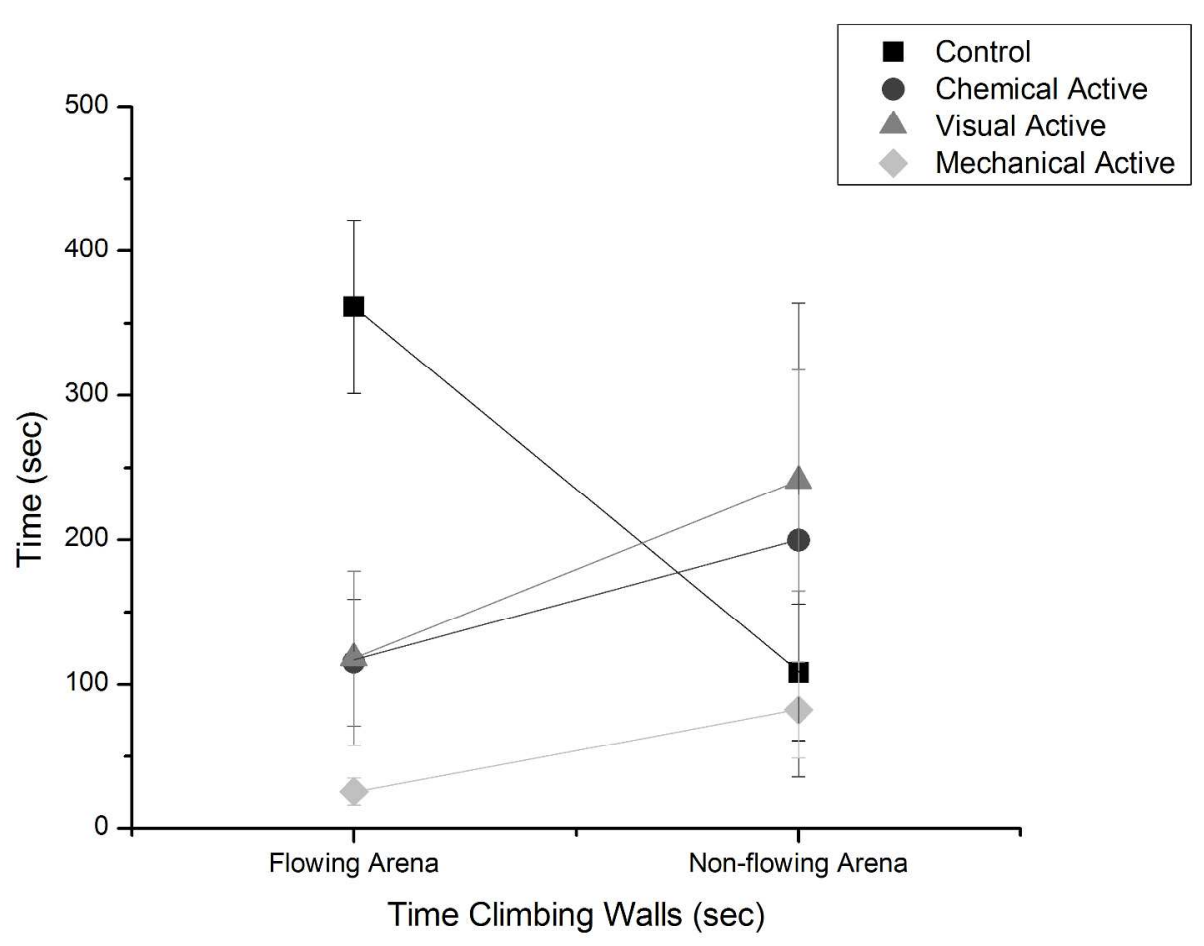

Figure 5

$279 \times 215 \mathrm{~mm}(300 \times 300 \mathrm{DPI})$ 